\title{
POLÍTICAS DE FORMAÇÃO CONTINUADA PARA PROFESSORES INICIANTES EM SOBRAL/CE
}

\section{CONTINUING TRAINING POLICY FOR BEGGINING TEACHERS IN SOBRAL/CE}

\author{
Zuleika Zamoner $^{{ }^{*}}$, Lilian Flávia Anorozo Nunes ${ }^{2}$, Thiago Rocha Amaro ${ }^{3}$, Patrícia Ortiz Monteiro ${ }^{4}$ \\ ${ }^{1}$ Mestre em Educação, UNITAU, Taubaté, SP, Brasil, zamonerzuleika@yahoo.com.br \\ ${ }^{2}$ Mestre em Educação, UNITAU, Taubaté, SP, Brasil, lifla1@outlook.com \\ ${ }_{3}^{3}$ Mestre em Educação, UNITAU, Taubaté, SP, Brasil, thiagoamaro06@gmail.com \\ ${ }^{4}$ Doutora em Ciências Ambientais, UNITAU, Taubaté, SP, Brasil, patyortizmonteiro@terra.com.br
}

\begin{abstract}
Resumo
O município de Sobral/CE vem protagonizando um espetacular caso de melhora de desempenho dos estudantes no Ensino Fundamental, a despeito do preocupante estado da educação no Brasil. Este estudo tem por objetivos: conhecer as políticas de formação continuada para os professores iniciantes deste município; analisar os dados oficiais das avaliações externas e; discutir a possibilidade de modelização dessa organização educacional. Estrutura-se como de natureza aplicada e descritiva, de levantamento bibliográfico, com abordagem qualitativa. Foram utilizados como instrumentos para a coleta de dados a entrevista e os formulários elaborados pelas autoras nas suas teses de doutoramento sobre o tema. Para análise dos dados coletados utilizou-se a técnica de análise de Conteúdo. Os resultados demonstram que a cultura organizacional e sedimentada em políticas públicas nesse município já está formalizada na legislação, apoia todo o sistema educacional e direciona os trabalhos diários nas escolas com o públicoalvo, que são professores e alunos. Verificou-se a continuidade dessa política, diferentemente do que se observa em outras regiões e municípios. As políticas públicas de formação inicial de Sobral repercutiram na vida do professor e do aluno, já que a ampliação do repertório cultural de um amplia a do outro. $O$ incentivo a cada dia e a busca pelo melhor que se pode oferecer para os alunos fez parte desse projeto.
\end{abstract}

Palavras-chave: Formação Continuada. Políticas Educacionais. Professores Iniciantes.

\begin{abstract}
The municipality of Sobral/CE has been leading a spectacular case of improvement in the performance of students in Elementary School, despite the worrying state of education in Brazil. This study aims to know the continuing education policies for beginning teachers in this municipality, analyze the official data from external evaluations and discuss the possibility of modeling this educational organization. It is structured as applied and descriptive in nature, based on a bibliographic survey, with a qualitative approach and content analysis. Interviews and forms made by the authors of the two doctoral theses on the subject were used as instruments for collecting data. The results demonstrate that the organizational culture and solidified in public policies in this city is already formalized in the legislation, supports the entire educational system and directs the daily work at school, with the target audience, which are teachers and students. The continuity of this policy is perceived, differently from what is observed in other regions and municipalities. Sobral's public policies for initial education had an impact on the lives of teachers and students, because the expansion of the cultural repertoire of one expands the repertoire of the other. The encouragement each day and the search for the best that can be offered to students was part of this project.
\end{abstract}

Keywords: Continuing Education. Educational Policy. Beginning Teachers. 


\section{INTRODUÇÃO}

A cidade de Sobral fica a $230 \mathrm{~km}$ de Fortaleza, capital do Ceará, Nordeste do Brasil. Fundada em 1.841, tem uma área de $2.130,56 \mathrm{~km}^{2}$ e sua população, em 2019 , foi estimada em 208.935 mil habitantes. Segundo dados do Instituto Brasileiro de Geografia e Estatística (IBGE), em 2017 a taxa de escolarização, para estudantes de 6 a 14 anos de idade, foi de 97,9\%. Alcançou projeção nacional, em virtude do Índice de Desenvolvimento de sua Educação Básica (IDEB) naquele ano.

Nos dados publicados pelo Atlas de Desenvolvimento Humano no Brasil, o Índice de Desenvolvimento Humano $\left(\right.$ IDHM $\left.^{5}\right)$ de Sobral era de 0,714, em 2010, que o município na faixa de Desenvolvimento Humano Alto (IDHM entre 0,700 e 0,799). A dimensão que mais contribui para o IDHM do município é Longevidade, com índice de 0,832 , seguida de Educação $(0,675)$, e de Renda $(0,647)$.

O município de Sobral/CE vem protagonizando um espetacular caso de melhora no desempenho dos estudantes no Ensino Fundamental, apesar do preocupante estado em que se encontra a educação no Brasil. Este estudo tem por objetivos conhecer as políticas de formação continuada para os professores iniciantes deste município, analisar os dados oficiais das avaliações externas e discutir sobre a possibilidade de modelização desse modelo de organização educacional.

André (2012, p. 115-116) observa que programas de iniciação à docência que incluam mecanismos de acompanhamento e capacitação "[...] podem ajudar a reduzir o peso dessas tarefas e fazer com que os iniciantes se convençam de quão importante é a adesão a um processo contínuo de desenvolvimento profissional". Segundo a autora, isso contribuiria para que as taxas de evasão da carreira dos docentes nos primeiros anos do magistério parassem de crescer.

Acredita-se na importância dos órgãos gestores de educação, aos quais cabe direcionar as políticas públicas, criar programas ou condições que favoreçam a transição de estudante a professor, preocupando-se com a inserção desse profissional e estabelecendo uma diferenciação entre formação inicial e continuada. Esse plano deve ter um sentido amplo de desenvolvimento profissional e ter continuidade após o estágio probatório.

\section{FUNDAMENTAÇÃO TEÓRICA}

Bueno (2002) aponta a importância de se pensar na formação do professor como um processo cujo início se situa "[...] muito antes do ingresso nos cursos de habilitação - ou seja, desde os primórdios de sua escolarização e até mesmo antes - e que depois destes tem prosseguimento durante todo o percurso profissional do docente" (Bueno, 2002, p. 22).

Tardif e Raymond (2000) explicam que boa parte do que os professores conhecem sobre a profissão e o ensino, sobre os papéis do professor, provém da sua própria história de vida como alunos. Os autores ponderam que os professores

[...] são trabalhadores que foram imersos em seu lugar de trabalho durante aproximadamente 16 anos (em torno de 15.000 horas), antes mesmo de começarem a

\footnotetext{
${ }^{5}$ O Índice de Desenvolvimento Humano Municipal (IDHM) é uma medida composta de indicadores de três dimensões do desenvolvimento humano: longevidade, educação e renda. O índice varia de 0 a 1 . Quanto mais próximo de 1, maior o desenvolvimento humano.
} 
trabalhar. Essa imersão se expressa em toda uma bagagem de conhecimentos anteriores, de crenças, de representações e de certezas sobre a prática docente (TARDIF; RAYMOND, 2000, p. 216).

Todo início de carreira tem suas dificuldades e desafios. A carreira docente não foge à regra. Todos os dias os professores iniciantes comparecem às instituições de ensino repletos de sonhos e medos, ilusões e decepções, acertos e erros. O fator que diferencia a atividade docente inicial das demais carreiras é o cenário educacional, que exige uma gama de habilidades para a sobrevivência do profissional iniciante. Todo auxílio, nesse momento, é extremamente importante, para que o docente iniciante se sinta amparado. Huberman (1992) afirmou que essas decepções do início da carreira são um tanto homogêneas, para os principiantes.

Temos um grande número de estudos empíricos sobre a escolha da carreira docente, e vários outros que tratam dos 2-3 primeiros anos de ensino. Se bem que as motivações sejam diversas, a tomada de contacto inicial com as situações de sala de aula tem lugar, por parte dos principiantes, de forma um tanto homogênea. Os que procuram descrever esta fase na óptica de uma sequência de fases que balizam a carreira (cf. Fuller, 1969; Field, 1979; Wats, 1980) falam de um estágio de "sobrevivência" e de "descoberta". O aspecto da "sobrevivência" traduz o que se chama vulgarmente o "choque do real" (HUBERMAN, 1992, p. 39).

Essa transição de estudantes a professores, segundo os autores Huberman (1992), Marcelo García $(2009,2011)$ e André (2012), vem sendo discutida como "choque com a realidade", conceito este popularizado por Simon Veeman' ${ }^{6}$ (1984, apud MARCELO GARCÍA, 2006, p. 7):

[...] la situación por la que atraviesan muchos docentes en su primer año de docencia. Según este autor holandés, el primer año se caracteriza por ser, en general, un proceso de intenso aprendizaje -del tipo ensayo-error en la mayoría de los casos-, y caracterizado por un principio de supervivencia, y por un predominio del valor de lo práctico.

Muitos autores relatam estes problemas no início de sua profissão e descrevem o contexto do exercício docente inicial. A realidade da prática educacional corrobora todas essas afirmações. A desistência de muitos profissionais competentes no início da carreira docente é elevada, uma das razões pode ser o pouco amparo que recebem nessa fase de turbulências.

Marcelo Garcia (2009) enumera os vários aspectos que agravam esse índice de desistência no início da carreira docente e descreve as situações que favorecem a desistência da profissão, tais como baixos salários, problemas de disciplina com os alunos, falta de apoio e poucas oportunidades para participação na tomada de decisões. Registra ainda a importância do equilíbrio emocional, nesse momento.

A inserção profissional no ensino é o período de tempo que abarca os primeiros anos, nos quais os professores hão de realizar a transição de estudantes a docentes. É um período de tensões e aprendizagens intensivas, em contextos geralmente desconhecidos, e durante o qual os professores principiantes devem adquirir conhecimento profissional, além de conseguirem manter um certo equilíbrio pessoal (MARCELO GARCÍA, 2009, 128).

Muitas das formações as quais os professores participam não satisfazem suas necessidades intelectuais e de motivação, nem as necessidades para melhorar a qualidade da aprendizagem de seus alunos. "Os compromissos e ligações emocionais dos professores com os alunos, quer sejam

\footnotetext{
${ }^{6}$ VEENMAN, S. Perceived Problems of Beginning Teachers. Revino of Educational Kesearch, 54 (2), 1984, pp. 143-178.
} 
positivos, quer sejam negativos, dão energia e articulam tudo o que eles fazem. Ensinar envolve uma grande dose de trabalho emocional" (DAY, 1999, p. 86). O desenvolvimento profissional do professor deve considerar os aspectos "[...] psicológicos e sociais que podem encorajar ou desencorajar a sua aprendizagem" (Ibidem, p. 87).

Dessa forma, constata-se a importância da formação inicial e continuada para o início da docência. Nóvoa (2017) menciona a importância de valorizar a preparação, a entrada e o aperfeiçoamento dos profissionais na educação. Esclarece que "[...] trata-se, no fundo, de responder a uma pergunta aparentemente simples: como é que uma pessoa aprende a ser, a sentir, a agir, a conhecer e a intervir como professor?" (NÓVOA, 2017, p. 113). Essa pergunta, aparentemente simples, requer uma reflexão profunda sobre o cenário da formação docente.

Primeiramente, há que se ressaltar a grande insatisfação com a formação inicial dos professores: um vasto universo, quanto aos desafios docentes, resumidos em conteúdos insatisfatórios para o cumprimento da tarefa de lecionar. Os estágios, que poderiam ser um espaço rico para a prática reflexiva, tornam-se enfadonhos, mal explorados, e os quesitos burocráticos constituem seu objetivo principal. Morgado (2011) destaca a importância de esses espaços serem destinados à preparação de profissionais capazes de responder aos desafios educativos que encontrarão.

Relativamente à formação inicial, entendida como uma etapa precedente à entrada na profissão, ao longo da qual se procura que os futuros professores adquiram conhecimentos e desenvolvam competências inerentes à tarefa educativa, constata-se que esta tem sido deficitária na preparação de profissionais capazes de responder aos desafios educativos de uma sociedade que rapidamente se tornou mais complexa e exigente (MORGADO, 2011, p. 802).

Nóvoa (2017) ressalta a importância do caráter híbrido da formação inicial, demonstrando que deve existir vínculo entre a universidade, as escolas e as políticas públicas. Explica que essa proposta estimula um lugar de diálogo que preza pela Universidade inserida na escola, bem como pela profissão no espaço de formação. Acredita-se que seria realmente importante essa ligação entre Universidade e instituição escolar, para que os formandos possam sentir-se seguros ao final da formação inicial.

Com relação às formações continuadas, num aspecto geral, são repletas de entraves. Existe o problema da descontinuidade. Geralmente as formações ditas continuadas são, na verdade, formações interrompidas a cada gestão governamental. A cada mudança partidária no cenário político, uma nova concepção formativa é ressaltada, e com isso interrompe-se o trabalho de formação que estava sendo desenvolvido. Muitas vezes as formações têm mais caráter motivador do que formativo. Morgado (2011, p. 803)) alerta para algumas das dificuldades da formação continuada:

Uma formação contínua, nasce da necessidade de cada profissional e se desenvolve conforme suas dificuldades são superadas. Só que, muito do que tem acontecido no terreno da formação contínua tem sido decidido pelo poder central e tem sido visto mais como uma obrigação e um requisito para a progressão na carreira do que como uma oportunidade de desenvolvimento profissional e uma possibilidade de transformar as práticas curriculares e os modos de trabalho no interior das escolas.

Dessa forma, a cada conhecimento novo e para cada superação em sala de aula, novos desafios nascem simultaneamente, exigindo dinamismo e habilidades que não são ensinadas num 
curso. Há necessidade, portanto, de reflexão sobre a prática, de uma análise do conhecimento adquirido e de postura do profissional para vencer os desafios cotidianos. Neste sentido, é fundamental o auxílio dos colegas de trabalho, tanto dos pares como da equipe gestora. 0 professor, que está sozinho, sente-se inseguro e, ao sofrer o "choque da realidade" pode desistir, por tantas pressões. A troca de informações com os colegas é fundamental, para que o professor iniciante supere esses momentos desafiadores e venha a conhecer uma gama de possibilidades e acertos já vivenciados por outros profissionais. Conforme ensina José Pacheco (2014):

Sabias que escolas são pessoas, comunidades feitas de pessoas, que aprendem umas com as outras. E que o desenvolvimento dessas comunidades depende da diversidade de experiências das pessoas que as integram, bem como requer que todos os membros que as constituem se envolvam num esforço de participação, da produção conjunta de conhecimento, vizinho a vizinho, numa fraternidade aprendente (PACHECO, 2014, p. 28).

Neste sentido, casos de sucesso precisam ser enfatizados. Uma formação de qualidade e com o atributo da continuidade é possível com o envolvimento da comunidade escolar, que passa a compreender sua trajetória, bem como a participar de seu planejamento.

Segundo André (2012), o município de Sobral/CE institucionalizou uma formação para os professores iniciantes. E regulamentou por meio de Lei Municipal n.671, de 10 de abril de 2006, uma formação continuada para os professores ingressantes na Rede Municipal. Conforme explica ANDRÉ (2012),

O programa consiste em uma experiência de formação e aprimoramento da prática pedagógica, considerada fundamental no desempenho profissional dos professores. A justificativa para o início do programa foi o resultado do concurso de 2005, momento em que foi detectada a necessidade de suprir lacunas na formação dos professores concursados. Segundo explicações da equipe entrevistada, tal iniciativa pretende capacitar adequadamente os professores para atender à demanda do município e aproximá-los de sua realidade educacional (ANDRÉ, 2012, p. 122).

De forma a assegurar os princípios constitucionais e a primazia da qualidade da educação, o município de Sobral/CE conseguiu amparar o professor iniciante e garantir uma formação continuada aos ingressantes na rede municipal. ANDRÉ (2012) aponta alguns importantes aspectos da formação em Sobral:

Outra obrigatoriedade a ser cumprida pelos professores é a participação de, no mínimo, $50 \%$ da carga horária no Programa Olhares, que busca ampliar o universo cultural dos professores, com uma programação anual que inclui conversas com artesãos, encontro com escritores, visitas culturais a museus, sessões de teatro e de cinema, oficinas pedagógicas com exposição dos docentes a diferentes linguagens, relatos de experiências exitosas e participação no Encontro Anual de Educadores de Sobral - um evento que reúne docentes da rede pública e privada do município (ANDRÉ, 2012, p. 123).

Percebe-se também preocupação com a formação continuada dos professores que já estão inseridos no sistema. Calil (2014, p. 216) descreve como é feita essa formação:

A formação em serviço dos professores da Rede Municipal de Sobral contempla todos os níveis de ensino, sendo promovida pela Escola de Formação em consonância com os objetivos da Secretaria Municipal de Educação de Sobral. A formação ocorre fora do ambiente escolar, normalmente no Centro de Convenções do Município. A carga horária compreende 8 horas mensais. 
Nessa formação continuada nota-se preocupação, não só com a metodologia do ensino, mas também com o oferecimento de um repertório cultural aos docentes. Assim, realiza-se uma formação completa, contínua e de qualidade. Ou seja, é oferecida uma formação que nasce a partir da realidade local, com participação dos docentes, visando ao enriquecimento pedagógico e cultural do público a ser atingido.

\section{MATERIAIS E MÉTODOS}

Esta é uma pesquisa bibliográfica sobre a formação continuada dos professores do município de Sobral/CE, especificamente dos professores iniciantes. Propôs-se fazer uma análise dos estudos sobre o tema a partir das linhas teóricas de Gatti (2009), Gatti et al. (2019), André (2012), Morgado (2011), Marcelo García (2009), Huberman (1992), entre outros, e sobre os dados estatísticos das avaliações externas padronizadas do IDEB $^{7}$ (Í́ndice de Desenvolvimento da Educação Básica, 2017), sendo analisados as metas correspondentes aquele ano, as notas

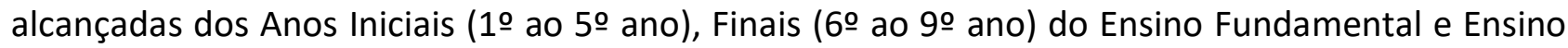
Médio (10 ao 3ㅇano) na Prova Brasil ${ }^{8}$, fazendo um comparativo a nível de Brasil e município de Sobral. O estudo consiste também da análise das teses de doutoramento de Calil (2014) e Becskeházy (2028) que foram realizadas sobre o caso de Sobral/CE, especificamente ligadas a educação e formação continuada. Os discursos coletados foram articulados com o apoio da técnica de Análise de Conteúdo de Bardin (1977).

De natureza aplicada, com abordagem qualitativa e de tipo descritivo, envolve levantamento bibliográfico, análise de uma entrevista semiestruturada com 13 perguntas realizadas via plataforma Zoom e de dois questionários respondidos pelos pesquisadores supracitados sobre o caso de Sobral, via formulário Google Forms, com 16 questões abertas sobre o tema da educação no município de Sobral e seus anseios e desafios em descortinar o tema em sua tese de doutoramento.

As seções foram subdivididas, a fim de dar visibilidade aos resultados. Foram identificados como elementos importantes para essa discussão: (i) as políticas de formação continuada dos professores iniciantes no município de Sobral (CE); (ii) As políticas públicas adotadas em Sobral podem servir de exemplo para obtermos melhoria no sistema educacional do Brasil? e; (iii) Qual o segredo de Sobral?

\section{RESULTADOS E DISCUSSÕES}

\subsection{Políticas de formação continuada dos professores iniciantes no município de Sobral/CE}

\footnotetext{
${ }^{7} \mathrm{O}$ IDEB é um indicador de desempenho da educação brasileira medido pelo Instituto Nacional de Estudos e Pesquisas Educacionais Anísio Teixeira (INEP), do Ministério da Educação (MEC). O índice é definido a partir do desempenho das disciplinas de Português e Matemática de alunos do 5o e do 90 ano do Ensino Fundamental e do 3을 ano do Ensino Médio. A taxa de aprovação, obtida pelo Censo Escolar, também é utilizada no cálculo da nota do IDEB, que vai de zero a dez (http://portal.mec.gov.br).

${ }^{8}$ Segundo o Ministério da Educação, a Prova Brasil e o Sistema Nacional de Avaliação da Educação Básica (Saeb) são avaliações para diagnóstico, em larga escala, desenvolvidas pelo Instituto Nacional de Estudos e Pesquisas Educacionais Anísio Teixeira (Inep/MEC). Têm o objetivo de avaliar a qualidade do ensino oferecido pelo sistema educacional brasileiro a partir de testes padronizados e questionários socioeconômicos (http://portal.mec.gov.br).
} 
O entendimento de políticas públicas normalmente está vinculado à ação do Estado e envolve iniciativas de investimentos, com prioridades e grupos atingidos em uma determinada área ou setor. No entanto, essas ações não nascem do próprio Estado; são decorrentes das demandas da sociedade (STUCKY, 1997). Segundo o autor, as políticas públicas geram visibilidade aos processos políticos e representam um compromisso público para atender às demandas de diversas áreas, inclusive priorizando as que estão voltadas à satisfação das necessidades básicas do ser humano. A educação é uma dessas áreas, que tem por objetivo a formação plena do ser humano.

Gatti (2009) observa que a formação, central nos processos educativos formais, deve caminhar na direção da preservação de uma civilização que apresente possibilidades melhores de vida e participação de todos. A autora evidencia que discutir e compreender "[...] a formação, as condições de trabalho e carreira dos professores, e, em decorrência sua configuração identitária profissional, se torna importante para a compreensão e discussão da qualidade educacional de um país" (GATTI, 2009, p. 90). A pesquisadora discute o amplo conceito de qualidade na educação e aponta a necessidade de qualificar a formação dos professores, tanto em graduações como em processos de educação continuada, formais ou informais, fora da escola ou dentro dela.

Day (1999) ressalta que a necessidade de melhorar os níveis de aprendizagem e atingir sucesso escolar está levando à políticas que se centram na qualidade pedagógico dos professores e do ensino. Afirma que esforços estão sendo feitos para garantir uma formação contínua frequente, para que "[...] possam atualizar o conhecimento do conteúdo e continuar a desenvolver estratégias relativas à organização da sala de aula, ao ensino e a avaliação e, quando necessário, ao desempenho de papéis de liderança" (DAY, 1999, p. 85).

Discussões sobre formação para iniciantes tiveram início no município de Sobral em meados da primeira década deste século (CALIL e ANDRÉ, 2016). Nesse momento também suscitaram discussões sobre o plano de carreira e a percepção de que era preciso dar suporte e apoio ao professor que estava ingressando. Foi criado então o Conselho Municipal de Educação, com o objetivo de constituir um grupo de trabalho para estudar as questões da carreira docente.

A ESFAPEM (Escola de Formação e Aperfeiçoamento Permanente do Magistério) foi criada em 2005, com o intuito de oferecer formação em serviço quanto à valorização do magistério, por meio de ações de formação pessoal e cultural - hoje ESFAPEGE (Escola de Formação Permanente do Magistério e Gestão Educacional). Percebendo as lacunas na formação dos professores recémingressados no concurso de 2005, o município "[...] reforçou a necessidade de um programa que atendesse aos professores que estavam iniciando sua experiência docente" (CALIL; ANDRÉ, 2016, p. 897).

O município de Sobral elaborou a formação para professores iniciantes, com participação compulsória, com o objetivo de aproximá-los da realidade educacional. Regulamentado pela Lei Municipal no 671, de 10 de abril de 2006, trata-se de um programa de 200 h/a, compulsório e remunerado (corresponde a $25 \%$ do salário de 40 horas), pois é realizado fora do período de trabalho. A exigência é de cumprimento de no mínimo $80 \%$ da carga horária total de 200 horas/aula. O primeiro formato do curso tinha como prioridade de formação as áreas de Português (60 horas/aula) e Matemática (60 horas/aula), com participação de todos, independentemente da sua área de atuação; Também eram oferecidos o Programa de Modificabilidade Cognitiva e Aprendizagem (30 horas/aula) e o Programa de Ampliação do Universo Cultural - Programa Olhares (50 horas/aula). 
Segundo as autoras, percebeu-se que os pedagogos, por serem polivalentes ${ }^{9}$, foram os mais privilegiados nesse modelo de formação. Uma nova proposta de formação foi organizada com a preocupação de preparar os professores para os desafios que se apresentam no exercício da profissão, quanto a conhecimento e à dinâmica de sala de aula, respeitando o ciclo de vida profissional que Huberman (1992) descreve. A nova proposta constituía-se, então, da seguinte forma:

\begin{abstract}
Modificabilidade Cognitiva - 40h/a; Contexto Escolar, 20h/a; Contexto Sociocultural, 20h/a; Relações Interpessoais na Escola e Ética Profissional, 35h/a; Didática e Metodologia de Ensino na Educação Básica, 35h/a; Formação Pessoal e Cultural, 30h/a (participação no Encontro de Professores do Projeto Olhares e em outras atividades do Projeto que totalizem a carga horária estabelecida); Apresentação dos Projetos de Pesquisa realizados durante a formação, 20h/a (CALIL; ANDRÉ, 2016 p. 899).
\end{abstract}

As autoras salientam que uma formação de 200 horas não supre todas as lacunas pedagógicas apresentadas pelos professores iniciantes, mas ao longo desse período é preciso considerar que eles estão "[...] 'assistidos pedagogicamente' em pelo menos três momentos: período do estágio probatório; formação realizada com os demais professores e planejamento, na escola, com o coordenador pedagógico" (CALIL; ANDRÉ, 2016 p. 900). Depoimentos extraídos do estudo de Calil (2014) explicitam a importância desse programa de estudos para os professores iniciantes:

[...] Ele não chega e fica... ele passa a perceber que a escola não é só a sala de aula dele. Que a escola é a escola toda, é o vigia, o trabalho e a comunidade [...] (DIRETORA DA ESFAPEM) (Ibidem, p. 135).

O estágio probatório é para o professor sentir o espaço escolar como espaço de construção pra formação dele. E a formação em serviço já tem outra estrutura que é a competência e o ofício do magistério, a competência pedagógica no sentido da eficiência do trabalho em sala de aula. A formação em serviço é voltada pra o que acontece dentro da sala de aula (DIRETORA ESFAPEM) (Ibidem, p. 136).

[...] Não tem como ser um bom professor se você não tiver sendo influenciado a todo o momento. Sem essa troca de experiências, e é claro, a Secretaria tem que fazer isso nem que seja obrigatório mesmo (Ibidem, p. 137).

André (2012) destaca a importância de políticas voltadas aos professores iniciantes e de programas que favoreçam a inserção à docência. Segundo a autora, esse tema necessita de um estudo mais profundo, para análise do futuro dos recém-graduados na carreira docente e para compreender esse processo inicial frente à prática da sala de aula e aos alunos.

Cabe lembrar que nesse município os professores iniciantes frequentam tanto as formações específicas, quanto as formações em exercício realizadas para todos os professores da rede.

O município de Sobral seguiu um plano de metas que incluía: no ensino fundamental, Alfabetização na idade certa (1으 e 2음 ano), Alfabetização dos alunos do 3 ㅇ ao 5음 não alfabetizados e Proficiência em português e matemática para os alunos já alfabetizados. Com essas metas a serem atingidas, buscaram fortalecer a gestão, a ação pedagógica e a valorização do magistério. Para isso, foram realizados concursos para gestores, formação em serviço com mudanças na rotina estruturadas na sala e material pedagógico para professores e alunos, concursos e reajustes

\footnotetext{
9 O professor polivalente é aquele que leciona nos anos iniciais do Ensino Fundamental, habilitado a atuar em
} diferentes áreas do conhecimento. 
salariais para professores. Foi criado o Prêmio Escola Alfabetizadora/ Prêmio Escola de Sucesso e instituiu-se bônus para aquisição de computadores. Além disso, incentivo salarial mensal diferenciado a partir dos resultados das aprendizagens e criação do programa Olhares, para ampliar o olhar cultural dos docentes (CALIL, 2014).

Sobral investiu em kits de materiais escolares; para professor, mensalmente, que os recebia nas formações, e para cada aluno, entregues bimestralmente. Além disso, materiais, livros e brinquedos para as escolas. Foram oferecidas aos alunos aulas de recuperação no contraturno, e de aulas de música, teatro, capoeira, esportes, visando à formação integral dos cidadãos sobralenses. A autora salienta que o salário do quadro do magistério havia recebido aumento de 375\% (Ibidem.)

\subsection{As políticas públicas adotadas em Sobral podem servir de exemplo para se alcançar melhoria no sistema educacional do Brasil?}

Segundo Calil e André (2015), as discussões sobre a formação para os iniciantes tiveram início em meados dos anos 2000, quando ocorreram também discussões sobre o plano de carreira e a percepção de que era preciso dar suporte e apoio ao professor que estava ingressando.

As autoras relatam que a proposta de formação para os professores iniciantes contou com o apoio do Conselho Municipal de Educação, que constituiu um grupo para estudar as questões da carreira docente. O que levou a implantação do programa foi o perfil dos professores ingressantes no concurso de 2005, pois foram percebidas lacunas na sua formação. Tal fato reforçou a necessidade de uma formação para esses professores iniciantes na profissão docente.

A intenção do programa de formação na cidade Sobral era levar os professores a conhecerem melhor seu ambiente de trabalho e, segundo Calil (2014), provocar reflexões sobre as necessidades da prática e sobre a dinâmica do contexto escolar em que atuariam. Cabe ressaltar a importância da formação cultural que o Programa Olhares proporciona aos professores iniciantes, que se sentem motivados "[...] ao descobrirem um universo cultural que thes amplia a visão e, ao mesmo tempo os faz valorizar profissionais locais de outras áreas que até então desconheciam" (CALIL, 2014, p. 167). As vivências possibilitam a inter-relação entre a cultura local e a universal, ampliando a visão cultural com outras leituras e linguagens dos professores de Sobral ${ }^{10}$.

Os reflexos do trabalho de formação realizado com os professores de Sobral repercutem nos dados oficiais, como o IDEB, no qual na edição de 2017, o município alcançou a maior nota do Brasil nos Anos Iniciais e Finais do Ensino Fundamental, ultrapassando a média nacional em mais de três pontos.

A evolução educacional ocorrida no município de Sobral é observada nas avaliações de desempenho realizadas pelos alunos do município. Contudo, André (2012) ressalta a preocupação de que é preciso tomar cuidado com essa mensuração, pois o esperado é que as ações formativas se revertam em aprendizados. É preciso cautela quanto ao modo como essas avaliações são utilizadas. Isso porque, ao serem privilegiadas as disciplinas Matemática e Português, ocorre um empobrecimento curricular e pratica-se um ensino que prepara apenas para testes.

\footnotetext{
${ }^{10}$ O programa Olhares proporciona momentos de ampliação do repertório cultural dos professores, e é planejado de forma diversificada com o intuito de acolher a todos os professores iniciantes, experientes e de outras redes de ensino. São proporcionados nesses encontros massagem, dança circular, Karaokê, cinema, visitas a exposições entre outras atividades. Destaco o momento da Tribuna, onde nos encontros anuais, são feitas inscrições antecipadas e o professor tem 30 segundos para pôr a "boca no trombone", o que acaba por ser um momento de desabafo, um momento reservado para o professor se expressar e ser ouvido.
} 
Neste estudo são apresentados os resultados das últimas avaliações e o índice do IDEB do município, na tentativa de observar a abrangência das políticas públicas instaladas em toda sua rede de ensino e sua repercussão na aprendizagem dos seus alunos.

O município ultrapassou as metas estabelecidas pelo IDEB em 10 anos. Em 2007, para os Anos Iniciais do ensino fundamental, a meta era de 4,0, e atingiram 4,9. Em 2017 estava estabelecido para esse mesmo segmento uma nota de 5,6, e os alunos conquistaram a nota 9,1, a mais alta de todo o Brasil. Resultado positivo também foi observado nos Anos Finais, que em 2007 tinham uma meta de 3,3 e atingiram a nota 3,5, passando para uma meta de 4,8, em 2017, e conseguiram ultrapassar, chegando a 7,2. A Figura 1 apresenta as notas obtidas pelo município de Sobral em relação à média nacional nessa avaliação.

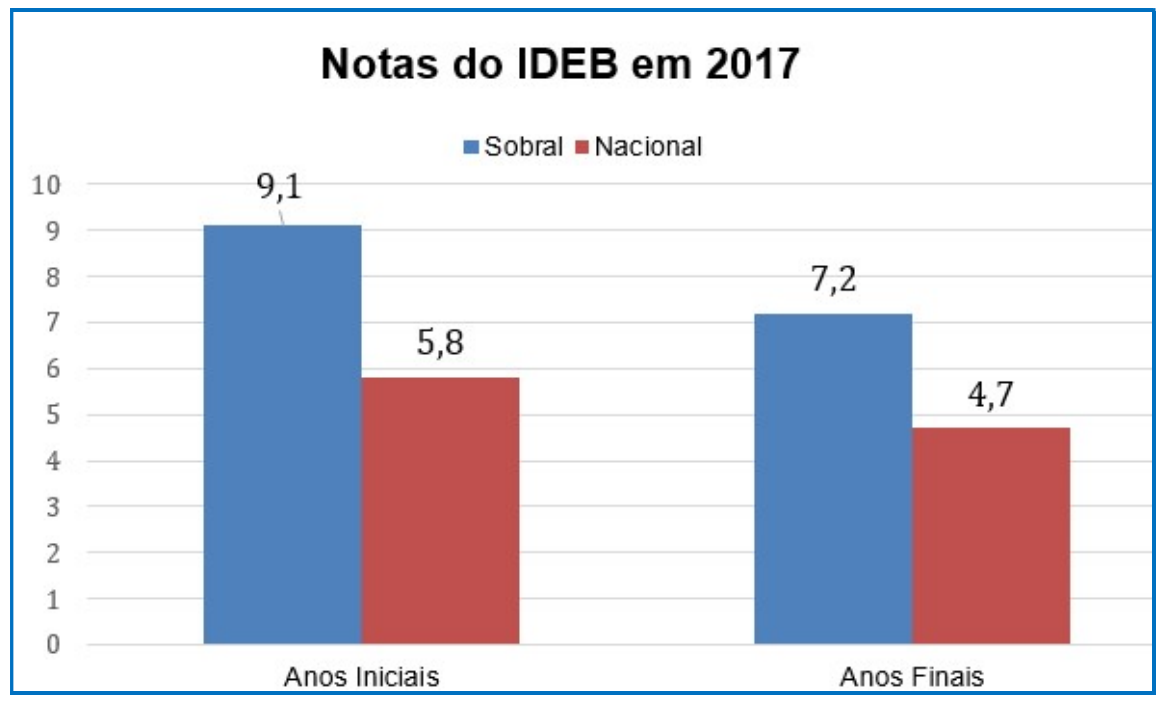

Fonte: Elaborado pelos autores.

Figura 1 - Notas do IDEB em 2017

As participantes entrevistadas neste estudo são duas pesquisadoras que estudaram o tema abordado nesta pesquisa. E os resultados das entrevistas serão destacados a seguir

Segundo a Participante 1, Sobral é hoje um "padrão ouro", um exemplo muito significativo de educação eficaz pautada em uma dura rotina de estudo e dedicação de todos os envolvidos no processo educativo.

Sobral hoje, para mim, poderia ser chamada de "padrão ouro" de gastos per capita com educação: quem gasta mais e não consegue os mesmos resultados, está jogando dinheiro fora, quem gasta menos não poderia ser esperado chegar no mesmo nível. Entretanto, como eu mostro na tese, outros municípios, no mesmo estado e com gastos próximos, não chegam ao mesmo nível de ensino, pois montar uma rede com essa competência técnica depende de decisões políticas consistentes ao longo do tempo (Participante 1).

Becskeházy (2018), que associa Sobral a Shangri-La ${ }^{11}$, percebeu que suas escolas oferecem aos "filhos da sua terra" um processo de alfabetização da melhor qualidade. Explica que tinha

\footnotetext{
11 Shangri-La, da criação literária do inglês James Hilton, Lost Horizon (Horizonte Perdido) de 1933, é descrito como um lugar paradisíaco, situado nas montanhas dos Himalaias, sede de panoramas maravilhosos e onde o tempo parece
} 
como objetivo de pesquisa descobrir exemplos das reformas educacionais de qualidade e equidade e que decidiu que ia começar por Sobral, quando conheceu a educação desenvolvida no município.

Os veículos de comunicação vêm publicando notícias sobre o ensino de Sobral, tendo em vista o evidente crescimento nos índices educacionais. Passaram a ser vistas manchetes como: "Educação de qualidade: o exemplo de Sobral", "Sobral (CE) ocupa primeiro lugar no Índice de Desenvolvimento da Educação Básica", "Escolas cearenses finalistas no Prêmio Respostas para o Amanhã precisam de votos". A Participante 1 acredita ser "[...] bom para que eles se sintam valorizados, mas tem atraído alguns predadores que vão lá com projetinhos de baixa qualidade, trabalham um pouco com a equipe e depois saem pelo Brasil vendendo como tivesse sido "made in Sobral".

Os resultados do município do interior do estado chamaram a atenção do próprio Estado do Ceará e de outros estados brasileiros, que passaram a se inspirar no sistema educacional fortemente estruturado na alfabetização na idade certa, na valorização do profissional da educação infantil, na gestão eficiente da escola e na formação continuada dos professores dentro da carga horária de trabalho.

Outros municípios estão seguindo esse modelo, inclusive em Estados como Goiás, Espírito Santo e Pernambuco, todos percebendo aumento nos índices e ficando entre os quatro primeiros colocados das redes estaduais no IDEB (2017) do Ensino Médio, como mostra a Figura 2.

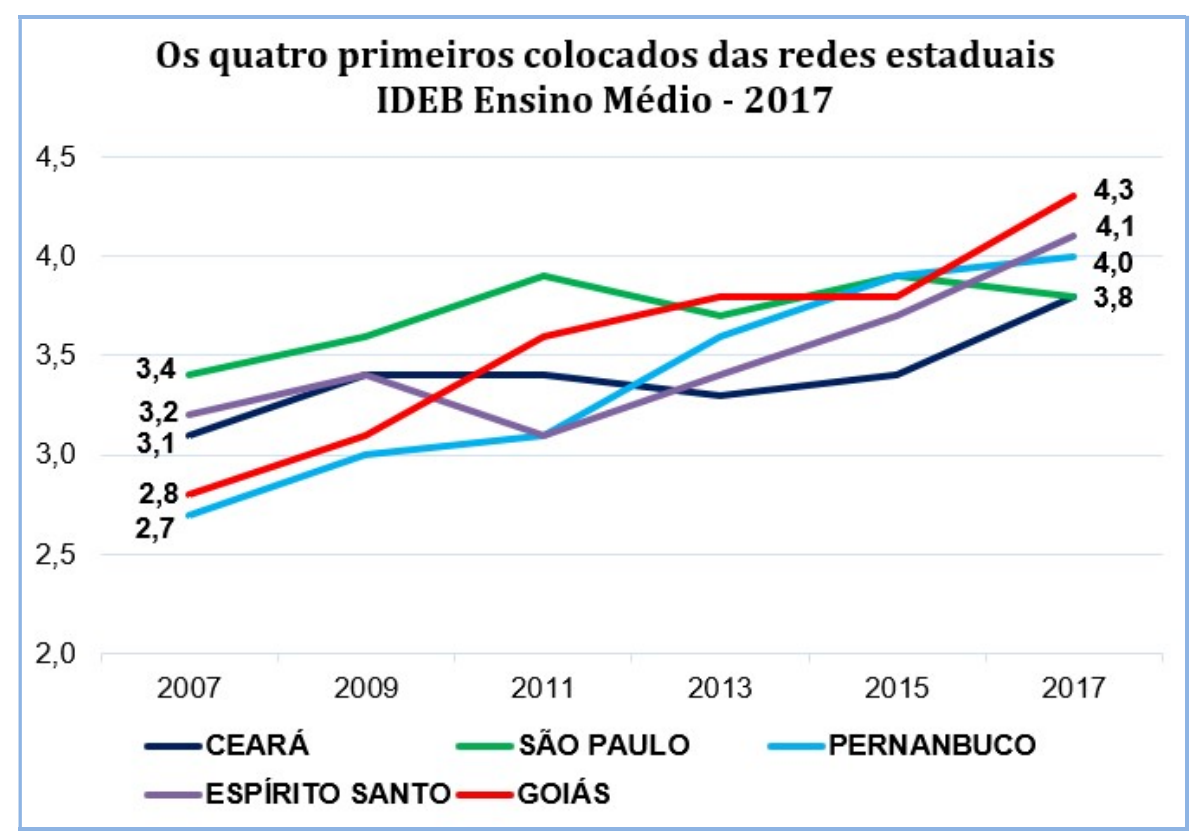

Fonte: https://www.qedu.org.br/. Elaborado pelos autores.

Figura 2 - Classificação IDEB no Ensino Médio em 2017

Ao analisar os dados do Ensino Médio, constata-se que o Estado do Ceará está entre os primeiros colocados, e que no município de Sobral o índice eleva-se para 4,3, maior que o do Estado. No entanto, esses índices estão distantes dos resultados do Ensino Fundamental da rede 
municipal de educação brasileira, pois o município atende apenas os segmentos da Educação Infantil e Ensino Fundamental. ${ }^{12}$

\subsection{Qual o segredo de Sobral?}

Os resultados descritos nas avaliações externas demostram a boa consecução de objetivos educacionais em Sobral/CE. Em virtude desse sucesso, foi aprovada pela Comissão de Educação, Cultura e Esporte (CE) uma proposta para que Sobral se torne a Capital Nacional da Educação, com a PL 3.700/2019.

Acredita-se que medidas como produzir material específico de alfabetização entregue para cada criança e dedicar-se a formação continuada para os professores, envolvendo-os como agentes fundamentais do processo, foram determinantes para Sobral conseguir esses resultados.

[...] A equipe foi sendo capacitada com base nos objetivos pedagógicos. Até o advento do novo currículo, esses objetivos eram uma combinação das provas locais, das estaduais e dos índices dos livros didáticos. A infraestrutura das escolas é a mais simples possível. Apenas recentemente é que estão sendo inauguradas escolas com estrutura mais "sofisticada". Mas até nós terminarmos nosso trabalho lá, em 2017, quase todas as escolas eram aquela estrutura típica das escolas construídas com verba federal na região norte e nordeste, de piso único, teto de telhas e janelas de tijolos cobogó (Participante 1).

Corroborando depoimento acima, Becskeházy (2018) explica que a realidade educacional de Sobral aponta seus próprios segredos, que são mistérios apenas para forasteiros, incluindo-se entre eles. Segundo a autora, são eles: liderança clara, objetivos explícitos, condições dignas de trabalho, valorização dos profissionais de ensino, imperativo moral de ensinar a todos, celebração diária da conquista e a humildade de saber que no dia seguinte todos esses compromissos precisam ser renovados. Sobral pratica a lógica das escolas eficazes, e o seu sucesso, segundo a autora, vem da competência do método de alfabetização escolhido, denominado Método Global, que parte do todo (textos, frases, palavras) para as partes (sílabas e letras) e do fato de a rede ter por meta alfabetizar todos no início da escolarização.

A Figura 3 indica uma tentativa dos autores deste estudo em expor a educação no município de Sobral. O texto foi elaborado a partir dos depoimentos dos participantes e das suas respectivas teses analisadas e organizadas.

Calil (2014) e Becskeházy (2028), que se dedicaram ao estudo sobre o sistema educacional de Sobral relatam que foram surpreendidos - "Foi um susto positivo!" -, pois descobriram lá equipes altamente qualificadas e acima de tudo com

[...] um compromisso moral muito forte com o aprendizado dos alunos, com justiça social e equidade. Há uma claríssima noção do que os alunos devem aprender a cada período letivo (semana) por disciplina, as decisões são tomadas em colegiado e há um sistema de controle que garante que o que é combinado realmente aconteça nas escolas, embora haja autonomia para decisões e adaptações ao nível de cada escola (Participante 1).

De acordo com Becskeházy (2018), Sobral valeu-se com competência dos instrumentos que foram dispostos pelo FUNDEF e pelo PDDE, preparando material estruturado para todas as salas de aula, bem como investindo na formação em serviço dos professores, que são aqueles que fazem a engrenagem girar. O caminho que o município construiu para a educação de seus

\footnotetext{
${ }^{12}$ As etapas de educação básica no Brasil organizam-se em: Educação Infantil, Ensino Fundamental (10 ao 9ㅇano) e Ensino Médio (1ㅇao 3o ano).
} 
conterrâneos foi sendo trilhado passo a passo, ou "ponto a ponto", como podemos observar no depoimento:

Durante o tempo em que estive lá, fiquei pensando muito no porquê de ser só lá e não em outro lugar? Na minha cidade, por exemplo! Eles foram criando o caminho ao caminhar. Ponto a ponto. Colocaram a Ed Infantil na pasta da educação, nuclearam as escolas rurais, fizeram blindagem na escola (vereador não dá palpite!), diagnóstico de alfabetização individual e não por amostra, investiram no diretor, investiram na alfabetização, foram estudar a alfabetização, designaram os professores para a alfabetização na Idade Certa. $\mathrm{O}$ PNAIC nasceu em Sobral. Depois investiram nos 4ㅇ e 5o anos. Posteriormente, nos anos finais. Criaram uma frente de valorização dos professores, fizeram parceria para a gestão de resultados. Tudo isso triangulado pela corresponsabilidade entre a Secretaria da Educação, a Esfapem (era esse o nome à época) e o pessoal da escola. Planejamento, acompanhamento rígidos e a bonificação por meritocracia. Da secretária da escola ao diretor, todos recebiam a bonificação por resultados. Ninguém descansa! O tempo todo pensando em melhorar. Cada prêmio que eles recebiam era revertido em formação, quer para diretores, quer para coordenadores (Participante 2).

\section{O CASO DE SOBRAL}

\begin{abstract}
Sobral pratica a lógica das escolas eficazes e 0 seu sucesso, segundo Becskeházy (2018), vem da competência do método de alfabetização escolhido.
\end{abstract}

Como será o

futuro dessa geração 9,1?

Espero saber sobre o ingresso no ensino superior, que tenham sucesso na profissão pela base que tiveram (Participante 2).

"Aqui não tem essa história de que pobre não aprende."

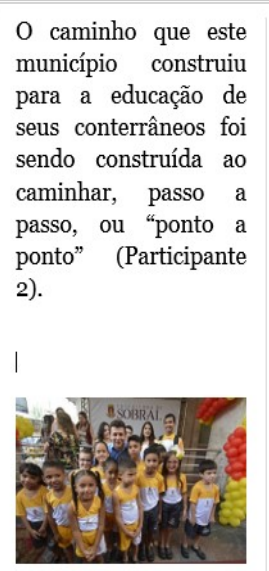

Colocaram a Ed Infantil na pasta da educação, nuclearam as escolas rurais, fizeram blindagem na escola (vereador não dá palpite!) diagnóstico de alfabetização individual e não por amostra, investiram no diretor, investiram na alfabetização, foram estudar a alfabetização, designaram os professores para a alfabetização na Idade Certa. O PNAIC nasceu em Sobral. [...]

Ninguém descansa! O tempo todo pensando em melhorar. Cada prêmio que eles recebiam era revertido em formação (Participante 2).

"Ninguém descansa! O tempo todo pensando em melhorar."

\section{Qual o} segredo de Sobral?

De acordo com Becskeházy (2018):

$\checkmark$ Liderança clara;

$\checkmark$ Objetivos explicitos;

$\checkmark$ Condições dignas de trabalho;

$\checkmark$ Valorização dos profissionais de ensino;

$\checkmark$ Imperativo moral de ensinar a todos;

$\checkmark$ Celebração diária da conquista;

$\checkmark$ Humildade de saber que no dia seguinte todos esses compromissos precisam ser renovados.

Fonte: Elaborado pelos autores.

Figura 3 - A visão de educação em Sobral/CE

A Figura 4 apresenta os princípios que o município adota em sua cultura organizacional, já institucionalizada.

Quando questionados sobre o futuro, sobre as perspectivas para os "filhos da terra", a resposta foi:

Penso que muitos poderiam voltar para a área da educação e continuar o trabalho que já foi feito com eles. Seria uma espécie de continuidade. Espero saber sobre o ingresso no ensino superior, que tenham sucesso na profissão pela base que tiveram. Quando entrevistei a superintendente de lá, ela me falou uma frase que me marcou muito. Ela 
disse "aqui não tem essa história de que pobre não aprende. Aqui tanto faz se é da cidade ou lá do distrito. Todos aprendem igual". Acho que essa equidade é o que estamos precisando. A chama acesa da potencialidade da aprendizagem de todos (Participante 2).

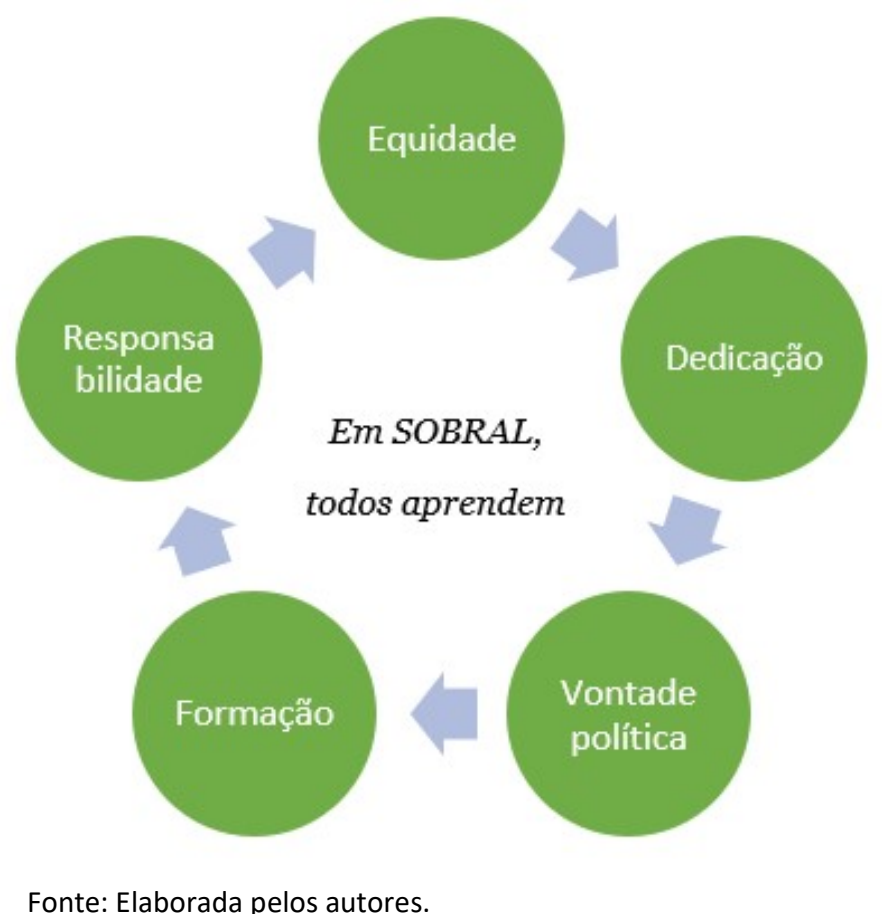

Figura 4 - Princípios educacionais em Sobral/CE

A ideia central que se extrai como ensinamento da experiência de Sobral é a de que "todos aprendem", como fica exposto na fala da Participante 2: não tem segredo, tem equidade, responsabilidade, dedicação e formação, aliando-se, a tudo isso, vontade política.

Acho que não tem segredo. Teve vontade política e esforço para que tudo desse certo. Eles queriam arrumar a educação e ser referência. Conseguiram. Fácil? Não! Requer boa vontade e apoio político. Investimento em formação e cobrança de resultados. Manutenção com alto nível de exigência. Uma máquina cheia de engrenagens trabalhando em sintonia. Em todo lugar há profissionais capazes, esforçados, sérios. No Brasil deveríamos e poderíamos ter muitas Sobral (Participante 2).

Quanto a replicar esse trabalho e obter os resultados de Sobral em outra esfera e realidade do país, um dos participantes acredita que "[...] é possível replicar essa política com a introdução de material altamente estruturado QUE CONTENHA os processos de ensino utilizados nos sistemas competentes dos países que conseguem educar todos os seus alunos" (Participante 1, grifos da pesquisadora) e salienta que o aparato de materiais e a organização estrutural e ideológica de tudo o que acontece no dia a dia das escolas em Sobral são fundamentais para os resultados lá obtidos. 


\section{CONCLUSÃO}

O modelo de formação inicial do município de Sobral/CE, desde que foi institucionalizado, indicou preocupação com as políticas públicas locais referentes à educação. Seu objetivo não era apenas melhorar a formação do professor ingressante, mas também oferecer formação continuada aos que já estavam no sistema, pensar na aprendizagem do aluno e na sua formação como sujeito cidadão, em sua formação integral. As políticas públicas de formação inicial de Sobral repercutiram não só na vida do professor, mas na do aluno também, uma vez que a ampliação do repertório cultural de um, amplia a do repertório do outro. Já que o professor é, muitas vezes, a figura inspiradora para o aluno.

O sistema de formação de professores, para os iniciantes e de formação continuada, e a proposta pedagógica do município de Sobral nasceu da realidade local, com a participação de todos, possibilitando o sentimento de pertença, quando os professores se sentiram parte do processo, e não membros isolados e desconectados. As exigências da educação tornam-se incentivo a cada dia, e a busca pelo melhor que se pode oferecer para os alunos é uma meta diária. Sua base de trabalho consiste no que existe de melhor em níveis internacionais e, de forma alguma, subestima os "filhos da terra", pelo contrário, acreditam no potencial de cada um.

Ressalta-se a cultura organizacional e sedimentada em políticas públicas naquele município, já formalizado na legislação, que apoia todo o sistema educacional e direciona os trabalhos diários na escola. Junto ao público-alvo, os professores e alunos, percebe-se a continuidade dessa política, o que não se observa em outras regiões e municípios. O programa vem mostrando seus resultados tanto nas avaliações externas, como no comprometimento de todos que lá trabalham e estudam. Experiências educativas que transformam e repercutem na formação integral do sujeito.

\section{REFERÊNCIAS}

ANDRÉ, M. E. D. A. Políticas e programas de apoio aos professores iniciantes no Brasil. Cafajeste Pesquisa, São Paulo, v. 42, n. 145, p. 112-129, abr. 2012. Disponível em: http://www.scielo.br/scielo.php?script=sci arttext\&pid=S010015742012000100008\&lng=en\&nrm=iso. Acesso em: 22 mar. 2020.

BARDIN, L. Análise de conteúdo. Lisboa: Editora 70, 1977. 229 p. Tradução de Luís Antero Reta e Augusto Pinheiro. Disponível em: file:///C:/Users/iccul/Downloads/BARDIN\%20-

\%20An\%C3\%A1lise\%20de\%20conte\%C3\%BAdo.pdf. Acesso em: 21 nov. 2020

BECSKEHÁZY, I. Institucionalização do direito à educação de qualidade: o caso de Sobral, CE. Tese (Doutorado em Educação) - Faculdade de Educação, Universidade de São Paulo, São Paulo, 2018. Disponível em: https://www.teses.usp.br/teses/disponiveis/48/48134/tde-04122018-175052/ptbr.php. Acesso em: 24 mar. 2020.

BRASIL. MEC. Decreto no 6.094 de 24 de abril de 2007. Dispõe Sobre a Implementação do Plano de Metas Compromisso Todos pela Educação.

Site QEDU.org.br. Disponível em: https://www.qedu.org.br/cidade/3692-sobral/ideb. Acesso em: 23 mar. 2020. 
BRASIL. Plano Nacional de Educação: olhares sobre o andamento das metas / Ana Valeska Amaral Gomes, organizadora. - Brasília: Câmara dos Deputados, Edições Câmara, 2017. Disponível em: http://bd.camara.gov.br/bd/handle/bdcamara/33101. Acesso em: 22 mar. 2020.

BUENO, B. O. O método autobiográfico e os estudos com histórias de vida de professores: a questão da subjetividade. Educação e Pesquisa, São Paulo, v.28, n.1, p. 11-30, jan./jun. 2002. Disponível em: https://www.scielo.br/i/ep/a/fZLqw3P4fcfZNKzjNHnF3mJ/?lang=pt\&format=pdf. Acesso em: mai. 2019.

CALIL, A. M. G. C. A formação continuada no município de Sobral (CE). 202 f. Tese (Doutorado em Psicologia) - Pontifícia Universidade Católica de São Paulo, São Paulo, 2014. Disponível em: https://tede2.pucsp.br/bitstream/handle/16139/1/Ana\%20Maria\%20Gimenes\%20Correa\%20Calil. pdf. Acesso em: 14 jan. 2020.

CALIL, A. M. G. C.; ANDRÉ, M. E. D. A. Uma política de formação voltada aos professores iniciantes de Sobral - CE. Revista Diálogo Educacional, [S.I.], v. 16, n. 50, p. 891-909, jul. 2016. ISSN 1981416X. Disponível em: https://periodicos.pucpr.br/index.php/dialogoeducacional/article/view/2884/2806. Acesso em: 22 mar. 2020.

DAY, C. Desenvolvimento profissional de professores: os desafios da aprendizagem permanente. Porto: Porto Editora, 1999. Cap. 3, p. 85-114.

GATTI, B. A; SÁ BARRETO, E. S; ANDRÉ, M. E. D. A. Políticas docentes no Brasil: um estado da arte. Brasília: UNESCO, 2011. 300 p. Disponível em: https://unesdoc.unesco.org/ark:/48223/pf0000212183. Acesso em: 14 abr. 2019.

GATTI, B. A. et al. Professores do Brasil: novos cenários de formação / Bernardete Angelina Gatti, Elba Siqueira de Sá Barretto, Marli Eliza Dalmazo Afonso de André e Patrícia Cristina Albieri de Almeida. - Brasília: UNESCO, 2019, 351p. Disponível em: file://C:/Users/iccul/Downloads/367919por.pdf. Acesso em: 25 mar. 2019.

GATTI, B. A. Formação de professores: condições e problemas atuais. Revista Brasileira de Formação de Professores - RBFP, vol. 1, n. 1, p.90-102, maio/2009. Disponível em: http://www.scielo.br/pdf/es/v31n113/16.pdf. Acesso em: 28 abr. 2019.

HUBERMAN, M. et al. O ciclo de vida profissional dos professores. In: Vidas de Professores. Portugal: Porto Editora, 1992. Disponível em: https://edisciplinas.usp.br/pluginfile.php/4955745/mod resource/content/1/Huberman-m-ociclo-de-vida-profissional-.pdf. Acesso em: 29 mar. 2021.

MARCELO GARCÍA, C. Desenvolvimento Profissional: passado e futuro. SÍsIFO, REVISTA DE Ciências da Educação. n.o 8, p. 7-22, jan/abr., 2009. Disponível em: http://www.unitau.br/files/arquivos/category 1/MARCELO Desenvolvimento Profissional Doc ente passado e futuro 1386180263.pdf. Acesso em: 20 jul. 2019. 
MARCELO GARCÍA, C. Políticas de inserción a la docencia: Del eslabón perdido al puente para el desarrollo profesional docente. PREAL - GTD (Grupo de trabajo sobre desarrollo profesional docente en América Latina), Bogotá, noviembre de 2006. Disponível em:

http://www.ub.edu/obipd/docs/politicas de insercion a la docencia del eslabon perdido al $p$ uente para el desarrollo profesional docente garcia c m.pdf. Acesso em: 30 mar. 2020.

MORGADO, J. C. Identidade e Profissionalidade docente: sentidos e (im)possibilidades. Ensaio: aval. pol. públ. Educ., Rio de Janeiro, v. 19, n. 73, p. 793-812, out./dez. 2011. Disponível em: https://www.scielo.br/pdf/ensaio/v19n73/04.pdf. Acesso em: 25 jun. 2019.

NÓVOA, A. Firmar a posição como professor, afirmar a profissão docente. Cad. Pesqui. São Paulo, v. 47, n. 166, p. 1106 -1133, dez. 2017. Disponível em:

http://www.scielo.br/scielo.php?script=sci_arttext\&pid=S0100-

15742017000401106\&lng=pt\&nrm=iso. Acesso em: 29 mar. 2020.

PACHECO, J. Aprender em comunidade. São Paulo: Edições SM, 2014. Disponível em:

https://cidadeseducadoras.org.br/wp-content/uploads/2018/04/aprender-em-comunidade.pdf. Acesso em: 2 abr. 2020.

STUCKY, R. M. M. As Políticas Públicas e a Exclusão na Conquista do Direito Universal à Saúde. In: BONETI, Lindomar Weller (Coord). Educação, exclusão e cidadania. ljúi: Unijúi, 1997.

TARDIF, M.; RAYMOND, D. Saberes, tempo e aprendizagem do trabalho no magistério. Educação \& Sociedade, ano XXI, n 209 o 73, 2000. Disponível em:

https://www.scielo.br/i/es/a/Ks666mx7qLpbLThJQmXL7CB/?format=pdf\&lang=pt. Acesso em: ago. 2019.

VEENMAN, S. (1984). Perceived Problems of Beginning Teachers. Review of Educational Research, 54(2), 143-178. In: MARCELO GARCÍA, C. Políticas de inserción a la docencia: Del eslabón perdido al puente para el desarrollo profesional docente. PREAL - GTD (Grupo de trabajo sobre desarrollo profesional docente en América Latina), Bogotá, noviembre de 2006. Disponível em: http://www.ub.edu/obipd/docs/politicas de insercion a la docencia del eslabon perdido al $p$ uente para el desarrollo profesional docente garcia c m.pdf. Acesso em: 30 mar. 2020. 